\title{
The Leap of Faith from Disease Treatment to Lifestyle Prevention: The Genealogy of a Policy Idea
}

Lars Thorup Larsen

For citing, please use this reference to the final, published version:

Larsen, Lars Thorup (2012): "The Leap of Faith from Disease Treatment to Lifestyle Prevention: The Genealogy of a Policy Idea", Journal of Health Politics, Policy and Law. 37(2): 227-52.

The published version can be accessed through this link:

http://jhppl.dukejournals.org/content/37/2/227

\begin{abstract}
Since the 1970s, public health policy has attempted to counter the rise of chronic diseases by getting individuals to make healthy choices about smoking, alcohol, diet, and physical exercise. Inspired by the so-called new perspective of the 1974 Lalonde report, this shift from disease treatment to prevention has been a key focus of public health policy to this day. Every generation of public health reports presents prevention as the answer to past failures, but the continuous experience of failure is strangely coexistent with a fundamental belief in the ability of lifestyle prevention to produce large health improvements. The article tracks the genealogy of lifestyle prevention as policy idea across three generations of U.S. and Danish public health reports and finds a systematic interpretation of lifestyle prevention as being more successful and promising than acute medical treatment.
\end{abstract}

\section{Introduction}

Since the 1970s, most Western countries have expanded their health policies with a strong involvement in disease prevention and health promotion, and in most cases, the main focus of these new policies has been on individual lifestyle. In what was broadly known as the "new perspective" on health policy, it came to be accepted as conventional wisdom that significant health improvements could be achieved through policies of individual lifestyle change, whereas no further 
health gains could be achieved through investments in acute treatment technology or, for that matter, traditional public health measures like sanitation and vaccination. Instead of trying to cure our way out of lifestyle diseases, it was widely held that we should try to change behaviors and prevent their onset in the first place.

Few people today would think that advances in medical technology had actually stopped forty years ago, so the "new perspective" did not lead to the planned shift from disease treatment to lifestyle prevention. The progress of medical treatment technology was believed to be in a crisis during this period, which has also been termed "therapeutic nihilism" (Starr 1976), but whether it was right or wrong, we still live with the consequences. Out of the disbelief in disease treatment grew a strong belief in promoting "healthy" individual lifestyle choices as a promising approach to public health policy. Since the birth of the "new perspective", the belief in lifestyle prevention has only grown stronger, but we seem to have forgot what conventional wisdom brought lifestyle-centered prevention onto the plate in the first place. What was the question that policies aimed at modifying individual lifestyle choice attempted to answer? The basic puzzle in this article is why lifestyle-centered prevention policies came to be seen as very promising. What was the source of the promise that policy makers suddenly saw in lifestyle choice as health policy approach and how was the faith in this idea reproduced later on?

The claim here is that policy makers' belief in lifestyle prevention as a policy approach was built on shaky ground from the outset. It is important to stress that it is lifestyle prevention as a policy idea - i.e. the ability of governments to make substantial health improvements by modifying individual lifestyle 
behavior - that is called into question here, not whether lifestyle and health are associated in general. However, even though the paper only aims to question lifestyle prevention as policy idea and not as health phenomenon, it is difficult to separate the two completely in the following analysis. The reason is that the former requires evidence of the latter, i.e. you cannot make an effective policy for healthy lifestyle changes without having at least some idea or knowledge about how lifestyle is related to health, which is not to suggest that having this knowledge would be sufficient. Furthermore, evidence linking lifestyle to health may be broad and well-founded today, but it was much more limited and of a very general nature back in the 1970 s when policy makers tried to use this knowledge as the basis for a new direction in health policy.

Belief in lifestyle prevention policies was essentially a leap of faith rather than based on solid experience. Most policy makers at this time simply chose to believe that substantial health improvements could be achieved through preventing unhealthy lifestyles. Understanding the original shift to lifestyle prevention is not only of historical relevance, however, because several generations of public health policies have continued to put new faith in the lifestyle approach. The purpose of this article is thus dual: first, to demonstrate what lines of reasoning were behind the birth of the 'new perspective' and its optimistic views of lifestyle prevention. Second, the aim is to show how new faith was put in lifestyle prevention through repetitive generations of public health reports from the 1970s to the present day. The two parts of the story are obviously connected, since part of what has made lifestyle prevention such a self-reinforcing policy idea is the appeal it had to policy makers in the first place. It is mainly about following the development of this idea from its inception to the 
present day including how prevention was always pitted against its alleged alternative, i.e. investments in acute treatment technology.

The genealogy here begins in the 1970s, because although treatment and prevention have always been juxtaposed, this period saw a new iteration of this classic public health discussion in which prevention was almost exclusively identified with individual lifestyle choice. It is the latter development that is the main topic here, and not the long history of public health from sanitation and immunization to this day (see Rosen 1993). This also means that the article inherits the terminological limitations of what is understood by the word prevention in the period studied. Unlike broader uses of this term that includes immunization, sanitation and much more, public health reports since the 1970 s tend to employ the term prevention more narrowly to indicate policies aimed at individual lifestyle choice. In lack of a better term, the article generally uses 'lifestyle prevention' to indicate this more narrow understanding of prevention. Also on terminology, the article uses 'lifestyle diseases' as the most common shorthand for the diseases targeted in these policy reports, which is typically lifestyle-related chronic diseases like cancer, cardiovascular diseases and diabetes.

The genealogical argument is based on an interpretive analysis of public health reports from the 1970s to the present day and with a dedicated focus on how these reports frame prevention and lifestyle as opposed to other health policy instruments such as acute disease treatment. Writing a genealogy is basically about disassembling or 'unpacking' (Bevir and Rhodes 2003: 107) the various elements that served to constitute a dominant discourse at a given time including what ruptures may have emerged in its meaning afterwards (Nietzsche 
1994; Foucault 2001). The purpose of disassembling the narratives in policy documents is not to test their status as true or false, since policy documents are obviously political and rarely live up to the rigorous standards of scientific arguments. So, while there is perhaps little novelty in showing that an old policy report jumps to conclusions or has a flawed line of argument, it might still be necessary to reconstruct these uneven elements if it helps to document the dominant beliefs of the time.

In order to be able to trace the continuous development of the lifestyle approach from one public health report to its successor, the article focuses on only two countries instead of trying to map the broad international diffusion of the idea. The core part of the article compares the major public health reports from the United States and Denmark since the 1970s, while the first part also include a Canadian report that was highly influential in the development of the 'new perspective'. The US and Denmark may seem like an odd couple in comparative policy studies, but there are nevertheless good reasons for selecting these two cases and look at the similarities between otherwise different health care systems. Looking at the US individually, one might be inclined to interpret the lifestyle approach merely as an input to the ongoing general debate about private and public health insurance, i.e. as a moral hazard argument about the irresponsible behavior of unhealthy people, which could serve to delegitimize proposals for public health insurance.

In a comparative light, however, this interpretation of lifestyle prevention is less plausible. Denmark is a country whose universal health coverage has been virtually uncontested for at least half a century, which makes it far-fetched to interpret the shift to lifestyle prevention simply as a cover for a 
rollback of public responsibility. Although it is definitely possible to frame unhealthy lifestyles as a moral hazard in public health, this was not what the genealogy of the lifestyle approach was mainly about, the article claims. By including both a private and a public health care system as cases in the comparison, the hope is to disentangle the belief in prevention somewhat from the surrounding political context. However, the comparison does not intend to take out the strategic or political element of health policy, but mainly to show how the strong belief in lifestyle prevention was not limited to specific ideological positions.

The main focus of the analysis is on how the public health reports understand the promises of lifestyle prevention as well as how they assess the success and failure of previous approaches. Sticking to a document analysis also leaves out a number of factors including for instance actors, institutions, implementation or the health economics of prevention. These are of course all relevant to the area of public health policy, but in order to trace the genealogy of lifestyle prevention as a policy idea, it is useful to use a somewhat narrower focus in this article.

\section{Birth of the 'New Perspective'}

The mid- to late 1970s saw the launch of a new type of public health report in both Denmark, the US and a series of other Western countries. Although there had been some public health reports on chronic diseases long before this period, the new reports established a comprehensive set of national public health goals including expected gains in life expectancy and most oftenly with a decade-long time frame. Also characteristic of this new group of public health reports is their 
consistent focus on lifestyle prevention, i.e. they are thoroughly preoccupied with chronic diseases now labelled lifestyle diseases and the proposed solutions are found outside the health care system, mostly in the form of expected individual lifestyle changes.

After several decades where most health policies had been preoccupied with technologies of disease treatment and expansions of the health care delivery, prevention was now launched as something completely new even though it had existed in public health for at least a century. Now rebranded as something genuinely new, lifestyle prevention was now at the center of public health policy laid out in these massive reports that constitute the core material of this analysis. The next section looks at the first generation of Danish and American public health reports in the late 1970s, while the latter part of the analysis moves on to the second and third generations of documents dating from around 1990 and 2000 respectively. Before digging into these documents, this section looks in more detail at some of the key ideas that went into the preventive turn and inspired public health reports internationally.

The term 'new perspective' comes from the seminal 1974 Lalonde report, which is properly titled $A$ New Perspective on the Health of Canadians (Lalonde 1974). It is worth to go back and revisit this document, not only because it was the key inspiration behind many later public health documents, but also because it gives a clear picture of how the prevention strategies were positioned very directly against the alleged failures of disease treatment. The document's core idea was to expand our understanding of what public health is and should be concerned with. The key notion is the so-called "Health field concept", which signals a broad field of intervention for public health policy that includes both 
human biology, environmental factors, lifestyle and the health care sector (Lalonde 1974: 32). Although these four parts of the health field are presented as deserving equal weight, there is no doubt from the rest of the document that its authors aim to boost the focus on individual lifestyle choice dramatically in exchange for a diminished focus on acute treatment in the health care sector.

The broad health concept had existed before in the context of the World Health Organization since this organization was established in the late 1940s, but the Lalonde report is probably the first policy document to take it one step further and directly link the perceived crisis of medical treatment with the new promises of prevention. This connection is established through what Marmor and Weale has properly termed a "potent brew" (2004: 36) of many different ideas ranging from medicine and population studies to natural theology and Chinese proverbs.

From the outset, the Lalonde report is aware of the possible critiques raised against the individual lifestyle focus. The document mentions the reservations that some might have against moralizing individual health behavior: "The ultimate philosophical issue raised by the [health field] Concept is whether, and to what extent, government can get into the business of modifying human behavior, even if it does so to improve health" (Lalonde 1974: 36). On this ethical question, the Lalonde report believes it is legitimate and even a necessity for governments to intervene given all the other "abuses" that individuals are already exposed to by television and commercial marketing techniques (Lalonde 1974: 36-7). Interestingly enough, the document also discusses the unwillingness of some individuals to change their habits in a healthy direction, but this is not seen 
as an obstacle to the effectiveness of the strategy, because the 'new perspective' can allegedly target individual motivation directly (Lalonde 1974: 6).

Besides problematizing individual lifestyle behavior, the Lalonde report builds on another narrative about health progress, which is probably one of the keys to understanding the strong belief in replacing disease treatment with lifestyle prevention. It is about a new interpretation of health progress in the past heavily inspired by the British medical historian Thomas McKeown, who showed that the major drops in British and Welsh mortality rates a century earlier were not the result of medical treatment or the progress of science. It was simply the effect of improved social conditions like better housing and nutrition, some of it being the result of the 'old' public health such as the sanitation movement. More than anything, it was McKeown's work that inspired the authors behind the Lalonde report to believe that medical technology could no longer improve health whereas the new perspective on lifestyle prevention could work as the natural successor to public health achievements in the past.

The key architect behind the Lalonde report, Canadian top bureaucrat Hubert Laframboise, cites McKeown as proof of the potentials of prevention: "His writings [i.e. McKeown's] proved that the improvement of the health status of the people was far more a consequence of changes in lifestyle and the environment than it was a consequence of advances in medical science" (Laframboise quoted in McKay 2000: 7). This quote illustrates how the new perspective was built on a highly questionable application of McKeown's studies. This faulty application of McKeown is one of the main sources of the leap of faith that lies at the heart of the new perspective, or to be even more precise, the series of leaps of faith. 
The first leap of faith lies in equating 19th century improvements to housing and nutrition with individual lifestyle choice. While some of the early conceptions of lifestyle (Coreil et al. 1985; Larsen 2010) did also include social living conditions, the Lalonde report is precisely characterized by not having a broad, social conception of lifestyle. Probably in part an effect of this report, lifestyle became an individualist concept that is almost synonymous with individual health behavior and choice, which has also been the subject of substantial critique in the public health literature (see Hunter 2003: 39; Journal of Public Health Policy 1980). With this in mind, it is basically a false implication when the Lalonde report takes McKeown as credit for what the individual lifestyle approach can achieve.

The second leap in the argumentation is between different types of diseases. McKeown's studies looked at infectious diseases, while both the Lalonde report and practically all the later public health reports studied here are almost exclusively concerned with lifestyle diseases. Again, the Lalonde report simply draws a false conclusion saying that a century-old drop in infectious disease rates can easily be replicated on lifestyle diseases in the present (see also Marmor \& Weale 2004: 38).

Even if we look aside the important distinctions first between living conditions and lifestyle choice and second between infectious and lifestyle diseases, there is a third leap of faith in the Lalonde report between epidemiology and public policy. There is no logical conclusion saying that because you can identify various disease-related lifestyle factors, these diseases are therefore preventable simply by the intervention of public health policy. In fact, McKeown himself warned that the explanatory factors he identified are "unlikely" (1979: 79) 
to exert the same influence in the future. The key point here is not just that Lalonde makes a questionable reading of McKeown, but to find out why the report is so optimistic about the possible health gains from lifestyle prevention, and it appears that the conclusions drawn from McKeown plays a significant role here. This is probably not a coincidence, because McKeown's work along with other writers like Illich came to symbolize a disbelief in medicine and acute treatment during this period, or what was also called the "therapeutic nihilism" (Starr 1979). Furthermore, the Lalonde report appears to believe that the growing skepticism about medicine in itself makes lifestyle prevention seem promising, and although there is no logical conclusion from one to the other, it appeared to be a strong argument for lifestyle prevention at the time. We will return to this policy leap later as it is repeatedly used in later public health reports to conflate statistical measures of 'preventable causes of death' with what governments can actually achieve through policies to modify individual health behavior.

\section{The First Generation of Public Health Reports 1977-80}

As mentioned earlier, the late 1970s saw the publication of new and comprehensive public health reports in the US and Denmark setting the public health agenda for the following decade or so. One key ambition of this generation of reports is to shift the priorities in health policy from disease treatment to lifestyle prevention, which is understood in the same way as Lalonde's new perspective. Another key characteristic is the selection of the four behavioral factors smoking, drinking, diet and physical activity as the main targets of public health policy. Some reports may occasionally mention accidents, drug abuse or 
sexually transmitted diseases, but smoking, drinking, diet and activity really are the four cornerstones of lifestyle-centered prevention from the 1970 s to this day.

The first major American public health report was launched in 1979 under the title Healthy People. The Surgeon General's Report on Health Promotion and Disease Prevention (DHEW 1979a; 1979b), which was completed by the following year's Objectives for the Nation (DHEW 1980). However, some of the core ideas had already been rolled out in several versions of the annual "Forward Plan for Health" in the preceding years, for example by emphasizing past failures and calling for an "aggressive prevention strategy" (DHEW 1976: 5, 70). The following passage from the 1976 forward plan is almost a direct quote from Lalonde: "[A]bsent any major scientific breakthrough such as a cure for cancer, the greatest benefits are likely to accrue from improved health habits rather than from further expansion of the health care system" (DHEW 1976: 5). The background papers to Healthy People repeats the exact same phrase and furthermore notes the "distinct limits to the ability of modern medicine to prevent these major ills" [i.e. lifestyle diseases] (DHEW 1979b: 425). Healthy People also refers directly to the Canadian Lalonde report and hails lifestyle prevention as "an idea whose time has come" (DHEW 1979a: 1-6, 1-9). Also very similar to Lalonde are the positive references to ancient Greek and Chinese conceptions of health and hygiene, which is juxtaposed to the negative views of modern medicine and the associated systems of health care and acute treatment (DHEW 1979a: 1-6).

Except for these more or less vague references to Lalonde, it is difficult to see what is the basis for Healthy People's assumption that scientific progress has come to a halt. It is simply taken for granted that medicine has lost 
the ability to improve health any further. Along with the lack of scientific progress, Healthy People identifies the previous health care priority for acute treatment technology as the main reason why the health of Americans is not what it should be. Like Lalonde, the report quickly leaps from the perceived deficiencies of medical treatment to the perceived potentials of prevention as if the former would somehow prove the latter. The report also makes the leap from epidemiological studies to policy potentials. For example, it cites Belloc and Breslow's (1972) study from Alameda County where disease rates were linked to simple healthy living rules (DHEW 1979b: 425-6). The Alameda Study only intends to provide statistical correlations and does not promise any massive health improvements resulting from lifestyle change nor does it have any suggestions for what policies can produce such changes. Similar to the faulty application of McKeown, the Alameda study is also taken as evidence that policies of lifestyle prevention are inherently promising. In other words, Healthy People proceeds as if this knowledge automatically translates into workable policies, i.e. it leaps from the epidemiological phenomenon to public policy. Similar leaps appear in this quote:

Simply by adopting the lifestyle of Seventh-day Adventists and moving to the Rocky Mountain States, US citizens could ensure for their children an incidence of cancer that was little more than half the national average, and they could do almost as well as this by becoming Mormons and migrating to Utah, or by migrating to Israel. It is perfectly reasonable for us to assume, therefore, that we could achieve as much reduction of cancer by appropriate steps in preventive medicine as our forebearers achieved for infectious diseases by improving public health. And the exercise is really to find out exactly which ingredients in our environment distinguish the 
Seventh-day Adventists, the Mormons in Utah, or the Jews and Arabs in Israel, from their counterparts in California, Illinois, or Pennsylvania. (DHEW 1979b: 165; cf. 1979a: 10-3)

It is not clear in the quote what the so-called 'reasonable' assumption in the middle is based on, i.e. how the argument leaps from identifying lifestyle and disease patterns to seeing the population's lifestyle behavior as being within the control of public health policy. These leaps of faith from Utah to California and from infectious diseases to lifestyle both underline the strong and taken-forgranted optimism of the early strategies in lifestyle prevention. This is perhaps expressed most clearly in the very first word 'simply'. Why it should be simple for a Californian to adopt the lifestyle of a Seventh-day Adventist is literally unclear in the report and definitely not an automatic effect of the epidemiological findings in the Alameda Study. Other parts of Healthy People are more concrete, but prevention is generally interpreted in much more positive terms than acute treatment and the expected health gains of prevention are often deduced from statistical correlations. For example, Healthy People contains a high-profile section on cancer and cardiovascular diseases - the two groups of diseases typically understood as lifestyle diseases. Here, the report argues that the statistical associations between the rise of lifestyle diseases and certain lifestyle factors in themselves give a " $\ldots$ tantalizing indication of the potential of prevention" (DHEW 1979b: 5). The quote shows how the public health report leaps from epidemiological risk information to policy potentials without giving much clue as to how governments can actually modify risky lifestyles in a healthy direction. 
It is important to mention one last factor in the way that Healthy People attributes success, failure and future promises to various public health approaches, which is the lack of specific policy instruments. Individual lifestyle choices constitute an important link between lifestyle diseases and the expected future health gains. Healthy People boldly states that people "must" make personal lifestyle choices in a healthy direction, but fails to develop what kind of policy would be needed to achieve these changes (DHEW 1979a: 2-8). The strong belief in the promises of individual lifestyle choice as public health approach is significant across the entire report, but aside from a few scattered discussions of health education the report actually contains very little in terms of policy instruments. Precisely why the policy side is so underdeveloped at this time is difficult to answer, except that the report seems to assume that large health gains will follow from knowing how health is lifestyle-related.

The basic message of the first Danish public health report from 1977 is fairly similar to its American counterpart despite the fact that it appears in a completely different health care system. The report was drafted by a commission with a Parliamentary mandate calling for 'health priorities' without any references to lifestyle or prevention. Even though it was not in the mandate, however, the commision clearly aims to put lifestyle prevention on the agenda as the main answer to the question about health priorities instead of trying to improve health through investments in the health care sector. There are no direct references to Lalonde and it is not clear what sources lie behind the recommendations about prevention, but the basic idea is the same. First and foremost, we should disconnect our understanding of health from the health care sector (Sundhedsprioriteringsudvalget 1977: 19). The report says that previous 
experience 'seems to suggest' that no major gains in the population's health status can be achieved through further resources for treatment technology (Sundhedsprioriteringsudvalget 1977: 51). Also, the commission 'assumes' that the largest health gains can be achieved through lifestyle prevention, but in spite of an initial wish to select preventive efforts based on what is proven efficient (Sundhedsprioriteringsudvalget 1977: 26), neither the negative view of treatment nor the optimistic view of lifestyle prevention are backed by much more than loose assumptions.

The latter part of the report offers some general reflections on the nature of preventive action, which serve here as suggestions for how to put the idea of lifestyle prevention into policy action. There are two inherent epistemological reasons why the superiority of prevention is difficult to document, the report argues. First, there is the so-called "paradox of prevention": "only when the possibilities of treatment seem to have dried out, does a growing interest in prevention spring forward" (Sundhedsprioriteringsudvalget 1977: 264). Paradoxical here is supposedly the ex post experience that a proactive intervention would have been better. Again, it is not clear what experience this evaluation is based on and the 'paradox' stands somewhat in contrast to a common sense statement later in the document saying that "... at all times it has been agreed upon that it is better to prevent than to cure" (Sundhedsprioriteringsudvalget 1977: 272).

In other words, there is some confusion as to whether lifestyle prevention is the right solution at this specific point in time, i.e. the result of experience, or whether it is simply understood as being ethically superior to acute treatment in general. The report formulates the long term ambition to reverse the 
paradox of prevention in the sense of only applying treatment in the health care system after all possibilities for prevention have been exhausted. It is not specified how health policy makers should do this in practice nor is there a corresponding reallocation of funds on the table, but suffice to say that the report entertains the idea of a substantial shift from treatment to prevention (Sundhedsprioriteringsudvalget 1977: 272).

The second epistemological problem raised in the report is the "dilemma of prevention", which means that although prevention is assumed to be the most successful strategy, the efficacy of preventive action can never be proven scientifically (Sundhedsprioriteringsudvalget 1977: 272). Intervention and result are often too far apart to assess causality not to mention the probabilistic nature of disease rates. If a major health problem is somehow avoided, it may have been prevented for entirely different reasons than health policy intervention similar to what McKeown found in 19th century Britain, or perhaps the expected health problem just never occurred in the first place. These reflections indicate a self-critical potential in the Danish report, which is also less critical of medicine than both its American and Canadian counterparts, perhaps because doctors were involved in the writing. It is also added that the shift to lifestyle prevention should not lead people to believe that their ill health could be blamed on the health care sector (Sundhedsprioriteringsudvalget 1977: 273).

Strangely enough, however, these critical reflections appear to have had little influence on the bold ambitions for lifestyle prevention in the rest of the report. The central message of the report remains that the Danish Government should prioritize a general shift of emphasis from disease treatment to lifestyle prevention, mainly based on relatively loose references to ideas about lifestyle 
factors and diseases popular at the time. Even though previous health education lessons have mainly documented what does not work (Sundhedsprioriteringsudvalget 1977: 277), the report says, lifestyle prevention is still presented as being inherently promising, which replicates the same leap of faith as above albeit with a few hints of self-criticism thrown in. Similar to the American report, the Danish report also expects the promises for future health gains to come mainly from individual lifestyle choice and not from disease treatment. The task of public health education is therefore to counsel and teach the individual citizen what is healthy and how to live by it, even though the report also states that the current abilities of the individual in this respect are quite poor (Sundhedsprioriteringsudvalget 1977: 30,275$)$. On the last point, it is characteristic that the first Danish report reflects on the (allegedly poor) abilities of the individual to make healthy changes, whereas the ability of governments to change individual behavior is unquestioned.

Both the Danish and the American reports devote the most considerations to make the general argument about the shift from disease treatment to lifestyle prevention and less so to describe how to get there. One remarkable similarity is that both documents claim that the shift towards lifestyle prevention is based on experience. For example, the American report claims to base the new policy on experience from the Alameda study and the Danish report makes vague references to what "previous experience" seems to suggest about the prospects of lifestyle prevention. In both cases, however, the sources of this past experience are systematically obscure and mostly look like watered-down ideas from Lalonde and, indirectly, McKeown. None of the reports provide any substantial evidence for the workability of a strategy based on individual lifestyle 
choice, because it appears as self-evident that prevention is a promising approach to public health. Indirectly, the strong faith in lifestyle prevention stems from the loss of faith in medicine and acute treatment technology at least in the area of chronic diseases, because the two approaches are clearly seen as being mutually exclusive. Since the belief in medicine to improve health was in free fall at the time, the so-called therapeutic nihilism mentioned before, prevention simply had to be promising.

\section{The Second Generation of Public Health Reports 1989-90}

Published around 1990, the second generation of public health reports develops a slightly more comprehensive idea about how to govern lifestyle behavior. However, considering the fact that the new reports should reflect a decade of experience from the first generation, it is remarkable to witness the repetition of the same leaps of faith as we saw before. Not only are both reports optimistic about the potential health gains of prevention, but they also present themselves once again as a major shift of emphasis in health care from treatment to prevention. Finally, the second generation reports are characterized by how they call into question the role of government in prevention, but whereas the Danish report seeks to replace government with individual responsibility, the American report describes a combination of individual responsibility with various levels of social engagement.

The second American public health report - titled Healthy People 2000 - was published in 1990, but the report was preceded by some debate about the previous course of action. One important critical voice was Louise B. Russell whose 1986 book Is Prevention better than Cure? gained substantial 
attention in health policy and public health circles in the US at the time. The book, which includes cost-benefit analyses not only of lifestyle, but also vaccination and screening technologies, challenged the underlying assumption in previous debates saying that it was always better and cheaper to prevent than to offer treatment (Russell 1986). In hindsight, however, the book was not able to eradicate the "persistent myth" (Russell 2009) that prevention saves money nor for that matter the optimistic view of what health gains prevention can achieve.

Rather than question the value of prevention, Healthy People 2000 launched as an even more ambitious strategy than its predecessor. Two years before the launch, the National Academy of Science had concluded that the nation had "lost sight of its public health goals and (...) allowed the system of public health activities to fall into disarray" (Institute of Medicine 1988: 19). In consequence, Healthy People 2000 could present itself as an answer to this situation of disarray and boldly declare the 1990 s to be "the decade of prevention" (DHHS 1990: vii; enclosure).

The report makes a great efffort of distinguishing itself from the first Healthy People report. The predecessor is now criticized as being "top-down, science-driven, and professionally dominated" and for giving too much weight to measures like morbidity, mortality and cost-containment instead of social concerns like quality of life (DHHS 1990: vii). In connection with this, the previous report is also criticized of too much blaming the victim and individualism, whereas the new policy should rather "spread the burden" (DHHS 1990: ix). These lines of criticism are relatively broad and refer to many different aspects of lifestyle prevention policy, but one common thread in them is a critique of the professional dominance of doctors or medicine in public health policy. The point here is not to 
assess whether the critique is right or not, but to notice the similarity with how the first Healthy People and especially the Lalonde report also considered doctors, medicine and conventional medicine to be obstacles rather than means to improving the health of the population. In other words, the second report criticizes the first report of being exactly what the latter tried to distance itself from. So, while the first Healthy People report asserted itself as a shift from disease treatment to lifestyle prevention, Healthy People 2000 attempts to make a similar shift once more. This shows how the shift from treatment to prevention is a narrative rather than actual stages of policy. When new policy documents distance themselves from the past, it is thus not about real events in the past, but a strategic platform for a new policy.

Another example of these strategic interpretations is how the second report assesses the more specific successes and failures of the first Healthy People. Only very few health factors such as infant and child mortality actually show progress since the last report, but it is not clearly explained why the report sees this as a success for a policy focused on lifestyle prevention. The point here is not the epidemiological question whether or not infant and child mortality are lifestyle-related, but only to point out that the report provides no evidence to suggest that the observed mortality drop is in fact an effect of the previous policy of lifestyle prevention. Again, an epidemiological phenomenon is taken as credit for public policy. The report also leaps from existing health problems to the gains of the new policy. After stating that the American people is currently burdened by "preventable illness, injury, and disability", the report quickly leaps to a very bold ambition saying that "The Nation has within its power to save many lives lost prematurely and needlessly" (DHHS 1990: 5-6). As if the 
very existence of preventable illnesses in a purely statistical sense would somehow make public health policy more powerful.

A new aspect of the preventive approach in Healthy People 2000 is the goal to reduce health disparities among Americans and achieve access to preventive services to the entire population (DHHS 1990: 43). The new report is thus not simply a repetition of the former, but contains a clearer acknowledgement that lifestyle prevention needs to incorporate the enviroment instead of just the individual. In doing so, however, the new report also tends to repeat the same unwarranted optimism as before. For example, it tends to interpret disease rates as a tremendous potential of the new strategy, which also serves to locate the reasons behind policy failure among weak subgroups in terms of race and social class instead of being a failure of the policy as such: "The greatest opportunities for improvement and the greatest threats to the future health status of the Nation reside in population groups that have historically been disadvantaged economically, educationally, and politically" (DHHS 1990: 46).

The identification of targets is obviously an important step in any intervention strategy, but nevertheless it is difficult to see why the identification of groups of unhealthy people should automatically make the policy goals within reach. What the focus on unhealthy groups of people does serve, however, is the broader normative argument in the report about responsibility. Healthy People 2000 talks a lot about "shared responsibilities" (DHHS 1990: 85) between individual, community, media, professionals and government, but these are rather broad obligations where it is not clear what the responsibility of each part is. Clear, however, is the ambition to put responsibility on the agenda, which not 
only resonates some of the Communitarian debates of the 1980s, but also resembles the contemporary Danish report.

The Danish public health strategy from 1989 consists of the Government's Prevention Program and the associated document Roads to Health for All (Ministry of Health 1989a; 1989b), but even seen together these two documents probably constitute the least ambitious policy analyzed here in terms of how much the Government wants to be involved in lifestyle regulation. For example, the report begins by stating that "many people" today point towards giving much higher priority to health promotion and lifestyle prevention while it is not entirely clear if the Government shares this point of view or not (Ministry of Health 1989a: 8). So, while the Danish Government is perhaps less enthusiastic about the prospect of interventions in individual lifestyle, it also shows that lifestyle prevention is still a dominant discourse that even a hesitant government feels it has to conform to. The Danish 1989 report is also less critical of medicine than the Lalonde report and the other documents analyzed here, but it nevertheless reproduces a very similar conclusion about the greater benefits of lifestyle prevention:

A disproportionate relationship has emerged between the results of treatment interventions on one hand -exceptional as they may be - and on the other hand those results and the accompanying quality of life that could have been sustained if the preventive intervention had been initiated in time and had been received by the population (...) By increasing the quality of life for coming generations of elders through a substantial intensification of preventive interventions on those who are now middle-aged, we can 
achieve a much larger effect on the general health status than is possible in most areas of the treatment sector (Ministry of Health 1989: 8, 14).

Similar to the other documents, the relationship between before and after is fairly confusing in this repetition of the narrative about the shift from treatment to prevention. It is not clear when the so-called "disproportionate relationship" has emerged, i.e. whether it merely diagnoses the same problem (too much treatment, too little prevention) as the former report did twelve years earlier or whether it sees the former policy as part of the problem. This is probably because the former report serves the dual purpose here of getting blamed for past failures while simultaneously being taken as evidence that lifestyle prevention is a promising way forward.

The vague assumption in the report saying that large health gains can be achieved through prevention also serves a different purpose in the 1989 report. Throughout the document, there is a clearer ambition to downplay government responsibility for the health of the individual whereas the American report aimed to promote the responsibility of all parts of society. Even still, both reports agree that not only government should have the main responsibility for lifestyle prevention and both emphasize the importance of responsibility in general, which resonates some of the Communitarian ideas popular at the time. Considering that it appears in the context of a health care system with public responsbility for the delivery, financing and production of health services, the Danish 1989 report makes a surprisingly strong appeal to individual responsibility for health. For example, the report says: "It is the obligation of society to provide the basis for making the healthy choice easy; but even considerable efforts in the areas under the control of society cannot solve the health problems caused by 
the individual's lifestyle" (Ministry of Health 1989a: 11). On the one hand, this sounds more modest than both the American and other Danish documents, but on the other hand we should remember that the report still claims that lifestyle prevention can produce large health gains, as the previous quote illustrated. Once again, it seems as if the promises of lifestyle prevention are assumed, but not documented or even just explained.

Another passage aims to downplay central government responsibility even further by stating that the decentralized health authorities should take a larger responsibility for prevention. The role of central government, on the other hand, should mainly be to "inspire" (Ministry of Health 1989b: 9). This rather vague ambition indicates a somewhat dissociated relationship between means and ends. On the one hand, it is claimed again and again that large health gains can be achieved through individual lifestyle choice, but the connection between the two is simply taken for granted and it is thus not clear how public health policy can ever cash in on these amazing promises. After saying that government cannot make individuals healthy, the document leaps to conclude that prevention "can achieve a much larger health effect than most areas of the health care sector" (Ministry of Health 1989a: 12). While it is obviously in line with the earlier attempts to talk down the role of government, it also appears to involve a completely unwarranted optimism on behalf of prevention, especially given the poor state that individual responsibility is allegedly in.

Like the first Danish report from 1977, one could say that the Government's Prevention Program is not as much a direct critique of medicine and the health care sector as it is a critique of our expectation that health care will 
come and save us if we live irresponsibly. In this way, it somehow takes the leaps and the uneven interpretations of disease treatment and lifestyle prevention from the 'new perspective' and then twists them into some sort of moral hazard argument about the lack of individual responsibility. The leaps are still there, of course, but in this second generation they can more easily be hidden under the alleged failures of the previous policies. In sum, the second generation of public health reports generally repeats the earlier arguments about a shift from disease treatment to lifestyle prevention and expands the belief in individual lifestyle choice with a concept of responsibility, although in the American version also with a stronger social focus and responsibility.

\section{The Third Generation of Public Health Reports 1999-2000}

Healthy People 2010 was published in 2000 and comprises the longest set of detailed public health goals and status indicators in this analysis, but the huge amount of numbers and measurements does not necessarily indicate a more workable approach to lifestyle prevention. In other words, there is a discrepancy in the third American report between a high level of detail on the one hand and an underdeveloped set of policy instruments on the other hand. In most respects, the document stresses the continuity with the former report and is thus less dismissive of earlier efforts in lifestyle prevention than we saw before. Most interesting here is the interpretation of previous successes and failures of the preceding policies:

One of the most compelling and encouraging lessons learned from the Healthy People 2000 initiative is that we, as a Nation, can make dramatic 
progress in improving the Nation's health in a relatively short period of time. For example, during the past decade, we achieved significant reductions in infant mortality. Childhood vaccinations are at the highest levels ever recorded in the United States. Fewer teenagers are becoming parents. Overall, alcohol, tobacco, and illicit drug use is leveling off. Death rates for coronary heart disease and stroke have declined. Significant advances have been made in the diagnosis and treatment of cancer and in reducing unintentional injuries (DHHS 2000: 3).

The quote sounds like a straightforward narrative about lessons learned, but while the former report did in fact claim that the 'Nation' could make dramatic health progress, it is difficult to see how this constitutes a lesson unless the claim itself serves as evidence. Furthermore, the previous report saw lifestyle prevention as the key to these great achievements, but in retrospect the quite few success stories in the report have nothing or little to do with lifestyle prevention. How can lower rates of teenage pregnancy reasonably be seen as successful goal attainment for a policy whose aim it was to get individuals to exercise more and drink, smoke and eat less? Also, while improvements in cancer diagnosis and treatment are definitely great health achievements, how can they reasonably be quoted as success stories of a policy whose basic premise was that health progress could not be realized through disease treatment? The key point here is not to dispute the achievements, but only to point out the creativity involved in portraying them as victories for lifestyle prevention. Again, public health reports attribute success and failure in a very uneven fashion. A new report may claim to build on experience, but what constitutes experience is filtered through a lens that always seem to understand lifestyle prevention as both the cause of past 
success and the road to health progress in the future. We will return to this pattern later.

Another significant aspect of Healthy People 2010 is a striking increase in the number of measurable targets, status indicators and very specific health goals. It appears to be inspired by New Public Management or similar ambitions to measure the success and efficiency of public action, but it also means going into very tiny details of everyday life. For example, one of the goals is to "Increase the proportion of persons aged 2 years and older who consumes at least three daily servings of vegetables, with at least one-third being dark green or orange vegetables (target: 50 percent)" (DHHS 2000: 19-20). This is just one example, of course, but the report contains long lists of similarly detailed goals and status indicators.

The large number of detailed health objectives does offer the potential to become more specific about what type of progress the policy tries to attain, but the specificity also comes at the risk of losing sight of what constitutes the overall strategy. At least, it is fair to say that Healthy People 2010 devotes much more energy to make detailed health goals than to specify the policy instruments by which a Government can reasonably expect to achieve the goals. This is more or less what happens when Healthy People 2010 measures the goal attainment of different sections in the previous report: none of the goals on family planning have been reached, 5 out of 27 goals on weight and obesity, 2 out of 20 on alcohol, 3 out of 26 on tobacco, and on diabetes the situation has moved even further away from the 1990 goals (DHHS 2000: 9-8, 19-8, 26-9, 27-8, 5-9). How these quite poor results add up to the overall experience of "dramatic progress" (DHHS 2000: 3, see earlier quote) is unclear, but the sheer amount of 
measurable targets makes it difficult to make any type of general assessment in a reasonable manner.

Similar to the earlier reports, Healthy People 2010 has great hopes for the future progress resulting from healthy lifestyles. It also builds on the idea of "shared responsibilities" between families, communities, businesses and government from the former report, but strengthens the focus on the individual. Despite the technical complexity of this 1,200-page document, this part actually speaks directly to each individual citizen by saying: "Whatever your role, this document is designed to help you determine what you can do (...) to help improve the Nation's health" (DHHS 2000: introduction - 4; emphasis in original). Although most of the report is of course aimed at local agencies and NGOs, the inclusion of segments addressed to the individual citizen illustrates the large ambitions of the massive document. Another possible interpretation is that to address the individual citizen directly signals a displacement from public involvement in the area, but still this would appear to be in conflict with the hugely detailed set of policy goals covering everything from fruit color to the consumption of various types of grains.

The Danish Government's Public Health Program 1999-2008 (Ministry of Health 1999) shares several key characteristics with the other documents, but it also makes a stronger call for public involvement in lifestyle prevention than its predecessor did ten years earlier. Among other changes, this step towards a much more ambitious public health policy is the result of the Median Life Expectancy Commission who made shocking headlines in the mid1990s when it was discovered that the Danish life expectancy had dropped considerably in international rankings (while still rising in absolute terms) (Højlund 
and Larsen 2001: 78-9). This is the background for the Health Minister's call for action in the introduction to the 1999 report:

Since 1970 development in life expectancy in Denmark has not followed the development in our neighbouring countries. (...) Our life-styles are to blame - tobacco, alcohol, accidents, too much fat and too little exercise. And these risk factors can be prevented. Although life-style is a matter of individual choice, the public authorities should explain in clear and unambiguous ways what makes people sick and how disease can be avoided (...) There is a need for a change of attitude. It is no use just to make light of the question of health in Denmark by joking about the boring Swedes and the crazy American smoking rules ((Ministry of Health 1999: 5)

The quote gives a clear diagnosis of how previous policies have failed, but the report still prescribes more of the same, i.e. a policy focused on individual lifestyle choice. The only way the report is able to recognize the failure of previous policies and still be optimistic about new policies of lifestyle prevention is by laying blame on the way Danes conduct their lifestyle and joke about health fanatics elsewhere. Later, the report also problematizes other established Danish cultural norms such as gender equality and the liberal upbringing of children, norms that are seen as being partly to blame for the unhealthy behavior of Danes (Ministry of Health 1999: 110).

Another way the 1999 report generates great expectations for the health gains of a stronger lifestyle approach is by putting a lot of faith in the power of knowledge and public communication, for example in this quote:

Social and cultural norms are not easily changed by individuals who adopt deviating views or behaviour. They are rather changed through political 
messages and points of view supported by arguments and followed by action. It is necessary that the public sector acts, takes a stand and starts a dialogue on risks (Ministry of Health 1999: 111).

This is very optimistic; especially considering that it is basically what public health policy has been doing since the creation of the 'new perspective', although with poor results in the Danish case. The quote also appears to describe some kind of public or democratic dialogue about healthy norm change, which mirrors the ideals of "democratic health promotion" popular in public health circles at the time (Jensen 1995). However, the democratic aspect stands in contrast to the very mechanical and administrative approach to health improvements suggested later on the same page:

The most important tool of the public health program is the creation of healthier settings for every day life. Therefore, the program contains targets for an overall effort to develop the comprehensive systems that constitute the framework for everyday health behaviour so that this framework will provide for a healthier and safer life for the population. This concerns schools, the workplace, the local community and the health services. The physical framework, work routines and rules should be carefully studied and examined from the point of view of their negative or positive influence on health. Organised follow-up of such studies will yield outcomes that will gain in importance by being spread to other areas of social life for instance via the family (Ministry of Health 1999: 111; emphasis in original).

The contrast between the two quotes is staggering, since the latter and more dominant approach throughout the report suggests that the Government scrutinizes every little aspect of social life in a systematic fashion in order to 
determine whether it contributes to health. Here, it is not about arguments and points of view, but about changing individual behavior in a healthy direction through whatever intervention is necessary.

The main point here is not whether this approach is legitimate, but rather that it is almost impossible to put into practice at least with the means sketched out in the 1999 report. Again, we see a leap of faith from having knowledge about the population's health to immediately expecting great health gains through government intervention. The same is characteristic of a new public health tool about making "health profiles", which are simply descriptions of the health status of a city, workplace, school or subgroup (Ministry of Health 1999: 91). The idea is clearly that profiling the health status will somehow lead to a process of health improvement, although the mechanism to make it happen is once again obscure. Given the unwillingness of Danes to make healthy changes in the past, these leaps from epidemiological knowledge to expected healthy changes across large and diverse subgroups of the population seem overly optimistic.

It is interesting to compare the American and the Danish public health reports from this third and last period, ${ }^{\mathrm{ii}}$ because the one reports 'dramatic progress' and the other reports a massive failure of previous policies. In this sense, the two country's reports are quite different with the American report focused on past successes and the Danish on what has gone wrong with the lifestyle of Danes. On the contrary, these differences have little influence on how much faith both reports still believe in the future promises of lifestyle prevention. Compared with the earlier periods, the later reports talk less about acute treatment as a direct alternative to lifestyle prevention, probably because the 
latter has established itself as an autonomous field in the meantime, but the belief in lifestyle prevention is nevertheless unchallenged. The early generations used a very clear dichotomy between disease treatment and lifestyle prevention, but this distinction blurs later such as when lifestyle prevention gets credit for cancer treatment, etc. One thing appears to remain constant despite disparities between periods, which is the leap from various kinds of past experience to seeing lifestyle prevention as the universal solution. In simplified terms, whatever has worked or failed in the past, a renewed focus on individual lifestyle choice must be the answer and often promises are built simply on identified "preventable" health problems. There is no way to prove that policy reports are literally 'untrue' neither is it the purpose. But the repetitive prescription of the same optimistic cure to whatever the diagnosis does suggest that perhaps the conclusion was given in advance.

\section{Conclusion}

This article has argued that public health policies have been dominated by the same dominant discourse about lifestyle prevention since the birth of the 'new perspective' in the 1970s. While throwing other types of prevention into the shadows and casting medical treatment in a negative light, this discourse has led us to believe that there was an easy fix to the problem of lifestyle diseases. Over and over again, the claim has been made that large health improvements can be achieved if governments "get into the business of modifying human behavior" as the seminal Lalonde report termed it. New policies have often been presented as 
a major shift from disease treatment to lifestyle prevention, but this shift is not only an old public health narrative. It also appears to be a remedy, which is prescribed independently of what actual health problems people may have and what health care they may have access to. These are the core elements of what constitutes lifestyle prevention as a policy idea whose origin lies in a leap of faith from epidemiological knowledge to thinking that governments can easily put this knowledge into action.

After disassembling some of the basic elements of this policy idea, the genealogy has also tried to demonstrate a pattern of interpretations across several generations of public health reports. Focusing on a pattern of interpretations obviously overlooks a number of other factors usually considered in health policy studies such as actors, interests and political ideologies. On the other hand, the genealogy also provides the opportunity for future studies to analyze the political interests in lifestyle prevention, for instance, in a new light. The same goes for the comparison between the US and Denmark, for while the analysis has shown some specific differences between Danish and American public health policies in various periods, the differences are by all normal standards smaller than we would expect them to be. This shows the tendency to systematically view lifestyle prevention as being a more promising policy approach than acute treatment.

The repetitive patterns of putting new faith in prevention every ten years indicate that even when public health reports claim to build on past experience, there is rarely a progressive lesson-drawing from one phase to the next. The later generations definitely provide more elaborate developments of policy instruments, measures and indicators, but the connections made between 
experience, problems and solutions are often still quite vague. The key aspect is how public policies build on previous experience, but never in raw form. Experience is always filtered through a lens that connects problems with solutions and decides what is seen as being successful or a complete failure. To say that policy makers see experience through a specific lens is probably an understatement, because often what is presented as experience is little more than vague references to historical developments in medicine or earlier epidemiological studies whose conclusions are stretched to legitimize a given policy course.

The article basically argues that it is this view of lifestyle prevention as being inherently superior that is false, but not necessarily the choice to advocate a preventive effort in a given empirical situation. The problem is that approaches centered on lifestyle prevention often leap too quickly from a tangible and measurable health phenomenon to believing it can fix the associated health problems. It is not that the health effects of dropping smoking rates or improved diets are not real, although it is worth to remember that knowledge of these effects was very sparse when lifestyle prevention became the dominant discourse. Lifestyle-related health problems are definitely real, but that does not mean that one should mistake statistically controlled 'preventable' lifestyle factors for something that falls within the range of political control.

One of the roots of this problem, the article claims, is the birth of the new perspective on public health in the 1970s, not least the influential Lalonde report whose ideas have had a major influence on public health policies to this day. Belief in the so-called 'therapeutic nihilism' was so strong at the time that policymakers apparently jumped to the conclusion that since health care could 
not improve health any further, prevention had to have this ability. The conclusion is not that we should avoid lifestyle prevention altogether and go back to only treating disease. Instead, we should simply recognize that the old proverb that prevention is better than cure is a truism, not a guideline for effective policies. The reason why lifestyle prevention is such a seductive idea may simply be that it looks like a 'free lunch' in the sense that one can avoid health problems altogether rather than having to deal with them. It is not a free lunch, however, but a 'resistible' development (Stone 1986) that can very easily deflate into the traditional blame and shame of individualist lifestyle policies.

* Acknowledgement: The author would like to acknowledge the help of Deborah Stone, the editor and two anonymous reviewers in providing useful comments and suggestions for improvement to earlier versions of this paper.

\section{References:}

Belloc, N. and L. Breslow. 1972. Relationship of Physical Health Status and Health Practices. Preventive Medicine 1, 409-421.

Bevir, M. and R.A.W. Rhodes. 2003. Interpreting British Governance. London: Routledge.

Coreil, J., J. S. Levin and E. G. Jaco. 1985. Life style - an emergent concept in the sociomedical sciences. Culture, Medicine, and Psychiatry 9: 423-437. 
DHEW (US Dep. of Health, Education, and Welfare). 1974. Forward Plan for Health for Fiscal Years 1976-80. Retrieved April 262011 from

http://rmp.nlm.nih.gov/RM/A/A/E/U/_/rmaaeu.pdf

DHEW (US Dep. of Health, Education, and Welfare). 1976. Forward Plan for Health for Fiscal Years 1978-82. Washington: Public Health Service.

DHEW (US Dep. of Health, Education, and Welfare). 1979a. Healthy People: The Surgeon General's Report on Health Promotion and Disease Prevention. Washington: DHEW.

DHEW (US Dep. of Health, Education, and Welfare). 1979a. Healthy People: The Surgeon General's Report on Health Promotion and Disease Prevention. Background papers. Washington: DHEW.

DHEW (US Dep. of Health, Education, and Welfare). 1980. Promoting Health/Preventing Disease: Objectives for the Nation. Rockville: Public Health Service.

DHHS (US Dep. of Health and Human Services). 1990. Healthy People 2000. Sudbury: Jones and Bartlett.

DHHS (US Dep. of Health and Human Services). 2000. Healthy People 2010. McLean: International Medical Publishing. 
Foucault, M. 2001. Nietzsche, la généalogie, I'histoire. In Dits et écrits I, 19541975, 1004-1024. Paris: Gallimard/Quarto.

Hunter, D. J. 2003. Public Health Policy. Cambridge: Polity Press.

Højlund, H. and L. T. Larsen. 2001. Det sunde fællesskab. Distinktion 3: 73-90.

Institute of Medicine. 1988. The Future of Public Health. Washington, DC: National Academy Press.

Jensen, B. B. (ed.). 1995. Research in Environmental and Health Education. Copenhagen: Danmarks Lærerhøjskole.

Journal of Public Health Policy. 1980. Editorial. Journal of Public Health Policy 1(1): 6-9.

Lalonde M. 1974. A New Perspective on the Health of Canadians. Ottawa: Department of Supply and Services.

Larsen, L. T. 2010. The Birth of Lifestyle Politics: The Biopolitical Management of Lifestyle Diseases in The United States and Denmark. In Governmentality: Current Issues and Future Challenges, ed. T. Lemke, S. Krasmann and U. Bröckling, 201-220. London: Routledge. 
Marmor, T. and A. Weale. 2004. Chapter 3: A New Perspective on Health:

Learning From Lalonde? In Fads in Medical Management and Policy, ed. T. Marmor, 36-47. London: The Nuffield Trust.

McKay, L. 2000. Making the Lalonde Report. Towards a New Perspective on Health Project, Health Network, CPRN, Background Paper.

McKeown, T. 1979. The Role of Medicine. Oxford: Blackwell.

Ministry of Health. 1989a. Regeringens forebyggelsesprogram. Copenhagen: Ministry of Health [quotes translated by author].

Ministry of Health. 1989b. Veje til sundhed for alle. Copenhagen: Ministry of Health [quotes translated by author].

Ministry of Health. 1999. Regeringens Folkesundhedsprogram 1999-2008.

Copenhagen: Ministry of Health [quotes from official English translation].

Ministry of the Interior and Health. 2002. Sund hele livet. Copenhagen: Ministry of the Interior and Health.

Nietzsche, F. 1994. On the Genealogy of Morality. Cambridge: Cambridge University Press. 
Rosen, G. 1993. A History of Public Health. Expanded Edition. Baltimore: Johns Hopkins University Press.

Russell, L. B. 1986. Is Prevention better than Cure? Washington, DC: The Brookings Institution.

Russell, L. B. 2009. Prevention Will Reduce Medical Costs: A Persistent Myth. The Hastings Center Health Care Cost Monitor, June 17.

Starr, P. 1976. The Politics of Therapeutic Nihilism. The Hastings Center Report 6(5), 24-30.

Stone, D. A. 1986. The Resistible Rise of Preventive Medicine. Journal of Health Politics, Policy and Law 11(4), 671-696.

Sundhedsprioriteringsudvalget. 1977. Betænkning fra sundhedsprioriteringsudvalget (commission report No. 809). Copenhagen: Statens Trykningskontor [quotes translated by author].

\footnotetext{
${ }^{\mathrm{i}}$ Two of the American public health reports (DHEW 1979a; DHHS 2000) do not use continuous page numbers, so the reference 1979a: 1-6 consequently refers to chapter 1, page 6, not pages 1 through 6 .

ii After a change of Government, a new public health report was released in 2002 under the title Sund Hele Livet (Healthy throughout life) (Ministry of the Interior and Health 2002), but since it is rather short and contains modest changes to the 1999 report, it is not included in the analysis here. The next American report Healthy People 2020 is currently in the middle of a consultation process.
} 